\title{
Intestinal Permeability is Increased in Children Born Preterm, with Persistent Growth Delay and Intrauterine Growth Restriction
}

\author{
Giorgio $\mathrm{V}^{* 1}$, Margiotta $\mathrm{G}^{1}$, Gallini $\mathrm{F}^{1}$, Leoni $\mathrm{C}^{1}$, Stella $\mathrm{G}^{1}$, Blasi $\mathrm{E}^{1}$, Onesimo $\mathbf{R}^{1}$, Persichilli $\mathrm{S}^{2}$, \\ Zampino $\mathbf{G}^{1}$, Gervasoni $\mathbf{J}^{2}$ and Gasbarrini $\mathrm{A}^{3}$ \\ ${ }^{1}$ Dipartimento di Scienze della salute della donna, del bambino e di sanità pubblica, Fondazione Policlinico Universitario A. \\ Gemelli IRCCS, Università Cattolica del Sacro Cuore, Rome, Italy
}

${ }^{2}$ Dipartimento di Scienze di laboratorio e infettivologiche, Fondazione Policlinico Universitario A. Gemelli IRCCS, Università Cattolica del Sacro Cuore, Rome, Italy

${ }^{3}$ Dipartimento di Scienze mediche e chirurgiche, Fondazione Policlinico Gemelli IRCCS, Università Cattolica del Sacro Cuore, Rome, Italy

*Corresponding author: Valentina Giorgio, Dipartimento di Scienze della salute della donna, del bambino e di sanità pubblica, Fondazione Policlinico Universitario A. Gemelli IRCCS, Università Cattolica del Sacro Cuore, Rome, Italy

\section{ARTICLE INFO}

Received: 罢 January 21, 2021

Published: 幽 January 27, 2021

Citation: Giorgio V, Margiotta G, Gallini F, Leoni C, Stella G, Blasi E, Onesimo R, Persichilli S, Gervasoni J, Gasbarrini A. Intestinal Permeability is Increased in Children Born Preterm, with Persistent Growth Delay and Intrauterine Growth Restriction. Biomed J Sci \& Tech Res 33(3)2021. BJSTR. MS.ID.005400.

\section{ABSTRACT}

Background and Aim: Recent studies have shown that prematurity might generate abnormalities of intestinal permeability (IP). Our pilot study has assessed IP in a cohort of preterm children with history of intrauterine growth restriction (IUGR) and persistent growth delay.

Patients and Methods: We reviewed clinical charts of preterm infants born between December 2010 and January 2015, selecting children above 4 years of age, born preterm ( $<36$ weeks), small for gestational age (SGA), with a documented history of IUGR and persistent stunted growth. Ten children ( 6 males, age range: 4-8 years), and 10 healthy controls (6 males, age range: 6.5-10 years) were assessed. All patients performed lactulose/mannitol (L/M) ratio test to evaluate IP.

Results: IP was significantly increased in patients compared to controls $(0.0945 \pm 0.063$ versus $0.0158 \pm 0.006$, respectively, $p<0,05)$, being pathologically high $(>0.003)$ in $100 \%$ of patients compared to $5 \%$ of healthy subjects.

Conclusions: IP is increased in preterm children with history of IUGR and growth delay at pre-schooler age, suggesting a role in their persistently poor growth. Further studies on larger series of children are needed to clarify the contribution of IP in the pathogenesis of restricted growth patterns.

\section{Introduction}

Intrauterine growth restriction (IUGR) is a clinical condition in which foetus cannot develop its own growth potential [1,2]. One of the mechanisms leading to IUGR is placental insufficiency [3], well studied in utero by doppler Fluximetry [4]. Because of hypoxia, foetus applies mechanisms of compensation -such as blood flow centralization (BFC)- causing, among others, enteral hypoperfusion. Data on how BFC during intrauterine life modifies development of the intestinal barrier and alterations of the intestinal permeability (IP) are scant [5].

IP is a property of the intestinal epithelium allowing molecules to pass through by non-mediated diffusion. The transport of molecules across the intestinal epithelium takes place via the transcellular and paracellular routes. Determining the urinary excretion of disaccharides and monosaccharides and the ratio of their excretion is a valid method for the measurement of IP. Monosaccharides, such as mannitol (M), pass through the transcellular routes, reflecting the degree of absorption of small molecules. Disaccharides, such as lactulose (L), pass through the intercellular junction complex, reflecting the permeability of large molecules. The $\mathrm{L}$ and $\mathrm{M}$ urinary excretion ratio is the most used test for the assessment of IP and eventually malabsorption [6]. The aim of this study was to evaluate IP in preterm children with history of IUGR and persistent growth delay at pre-schooler age, following 
the hypothesis that an increased IP may stay behind a chronic malabsorption and growth retardation.

\section{Patients and Methods}

We screened 1360 clinical charts of all patients followed at the Outpatient Clinic for Premature children of Fondazione Policlinico Universitario A. Gemelli of Rome, and selected those infants born between December 2010 and January 2015, of at least 4 years of age, with a fluximetry-confirmed history of IUGR and persistent growth delay -according to WHO growth charts [7]. Exclusion criteria were: patients diagnosed with diabetes, thyroid disease, previous abdominal surgery, congenital heart disease, kidney problems, connective diseases, CNS diseases or suffering from gastrointestinal diseases, viral hepatitis (HBV), autoimmune hepatitis, Wilson's disease, alpha-1-antitrypsin deficiency, use of drugs that alter carbohydrate metabolism, such as anti-epileptics, parenteral nutrition and use in the previous two months of NSAIDs, antibiotics, probiotics and drugs which alter gastric secretion. For the purposes of our study, we also excluded those who had adequate height and weight growth at time of evaluation, according to the WHO charts [7]. We enrolled a healthy age and sex matched control group, composed by children who were born at term, appropriate for gestational age (AGA), with an adequate growth trend at time of evaluation, with no history of drugs assumption influencing IP, in the last 3 months. Clinical history of all participants was collected as well as a food history after a 48 hours-recall.

\section{Lactulose/Mannitol Ratio}

All children underwent IP study by measuring the urinary L/M Ratio $[8,9]$. For the 48 hours before and during the test, all patients followed an elimination diet. Before starting the test, a pre-test urine sample was collected, added with $1 \mathrm{ml}$ of chlorhexidine and stored at $-20^{\circ} \mathrm{C}$. Subsequently a drinking solution, made of $1 \mathrm{~g}$ of Mannitol and $5 \mathrm{~g}$ of Lactulose melted in about $100 \mathrm{ml}$ of water, was administered. One hour after, the patients began collecting urine for the next 6 hours in a 24-hour container added with $1 \mathrm{ml}$ of chlorhexidine. At the end of the test, a $10 \mathrm{ml}$ aliquot of this urine was frozen at $-20^{\circ} \mathrm{C}$ and subsequently analysed. The patient's $\mathrm{L} / \mathrm{M}$ ratios were then compared with those obtained in the control group.

\section{Statistical Analysis}

Study data were entered into Excel spreadsheets (Microsoft, Redmond, WA, USA) and analysed with GraphPad PRISM software (version 5.1; GraphPad Software. Inc., San Diego CA, USA). Descriptive analysis was expressed as mean \pm standard deviation (SD) and percentages. Ordinal variables were evaluated using the nonparametric Mann Whitney test. A p value $<0.05$ was considered statistically significant.

\section{Results}

Epidemiological features and growth parameters of study population are summarized in Table 1 . Mean GE of cases was 29,2 weeks $( \pm 4,5)$, at birth mean weight was $702,5 \mathrm{gr}( \pm 240,2)$ and mean length $32,4 \mathrm{~cm}( \pm 2,8)$. As expected, weight and length at birth were significantly different between cases and controls. This data kept being significantly different also a time of last evaluation (Table 1). IP values measured by $\mathrm{L} / \mathrm{M}$ ratio were significantly higher in patients than in controls $(\mathrm{L} / \mathrm{M}$ cases $0.0945 \pm 0.063$; L/M controls: $0.158 \pm 0.06 ; \mathrm{p}<0.001$ ) (Table 1). All patients showed a pathological $\mathrm{L} / \mathrm{M}$ ratio - i.e., higher than 0.03 .

Table 1: Clinical features of patients and controls.

\begin{tabular}{|c|c|c|c|}
\hline & Controls & Patients & $\boldsymbol{p}$ \\
\hline Total N & 10 & 10 & \\
\hline Males N (\%) & $6(6)$ & $6(6)$ & $\mathrm{ns}$ \\
\hline $\begin{array}{c}\text { Age, years (median and } \\
\text { range) }\end{array}$ & $6,5(6-10,5)$ & $6,6(5-8)$ & $\mathrm{ns}$ \\
\hline $\begin{array}{c}\text { Birth weight, gr } \\
\text { (median and range) }\end{array}$ & $\begin{array}{c}3512(3250- \\
3750)\end{array}$ & $\begin{array}{c}672,5(450- \\
980)\end{array}$ & $<0,001$ \\
\hline $\begin{array}{c}\text { Length at birth, cm } \\
\text { (median and range) }\end{array}$ & $50(48,9-51,1)$ & $31,2(27-35)$ & $<0,001$ \\
\hline $\begin{array}{c}\text { Last visit weight, kg } \\
\text { (median and range) }\end{array}$ & $29,3(22,5-35,0)$ & $15,9(13,5-18,5)$ & $<0,001$ \\
\hline $\begin{array}{c}\text { Last visit height, cm } \\
\text { (median and range) }\end{array}$ & $132,7(124-$ & $109,5(100-$ & $<0,001$ \\
\hline L / M ratio (mean \pm SD) & $0,0158(0,006)$ & $0,0945(0,063)$ & $<0,001$ \\
\hline
\end{tabular}

\section{Discussion}

In our study we explored the hypothesis of an increased IP in children with persistent growth delay, history of IUGR and preterm birth. The blooming of the gastrointestinal (GI) system and development of the intestinal barrier is a dynamic process, still ongoing after birth [5]. BFC during intrauterine life has been hypothesized as one of the factors leading to an altered development of the intestinal barrier and alteration of the gut permeability. IP is a property of the intestinal epithelium allowing molecules to pass through by non-mediated diffusion. Determining the urinary excretion of disaccharides and monosaccharides and the ratio of their excretion is a non-invasive and easy-to perform method for the measurement of IP. The L and M urinary excretion ratio is the most used test for the assessment of IP [7]. Increased IP can lead to malabsorption; moreover, it augments the exposure of the entero-hepatic circulation to gut-derived bacterial products, such as lipopolysaccharides (LPS), determining a chronic lowgrade endotoxemia [6]. Following the hypothesis that BFC is linked to increased IP and malabsorption, we aimed to assess whether IP is increased in ex-premature children with history of IUGR and persistent growth delay.

The main finding of our study is the persistent increase of IP in paediatric patients born prematurely, with a documented history of IUGR and a persistent height and weight growth delay. This is the first study that highlights this data since others [1012] have observed an altered IP in animal models and in infants born prematurely within the $3^{\text {rd }}$ month of life. These findings may 
show that underlying the persistent growth restriction, there is a permanent state of "leaky gut" due to a TJ disruption process, finally leading to malabsorption. To modulate IP with a conscious use of pre and probiotics, may be an interesting perspective in this field. Gut microbiota may represent a new therapeutic target in paediatric growth restriction, when sustained by increased IP and malabsorption. Our study has some limitations. The main limitation is the small sample size and the retrospective recruitment of study population. The second one is the absence of a control group of children with a personal history of IUGR and preterm birth, but with regular growth. In conclusion, our study demonstrated a possible role of increased IP in growth delay of children born preterm with IUGR and growth delay. In the assessment of Pediatric growth delay leaky gut should be considered in the multidisciplinary evaluation to personalize treatment options.

\section{Conflict of Interest: None.}

\section{References}

1. Lausman A, Kingdom J, Maternal Fetal Medicine Committee (2013) Intrauterine growth restriction: screening, diagnosis, and management. J Obstet Gynaecol Can 35(8): 741-748.

2. Unterscheider J, Daly S, Geary MP, Kennelly MM, McAuliffe FM, et al. (2013) Optimizing the definition of intrauterine growth restriction: the multicenter prospective PORTO Study. Am J Obstet Gynecol 208(4): 290 e1-290 e6.

3. Morales-Roselló J, Khalil A, Morlando M, Papageorghiou A, Bhide A, et al. (2014) Changes in fetal Doppler indices as a marker of failure to reach growth potential at term. Ultrasound Obstet Gynecol 43(3): 303-310.

\section{ISSN: 2574-1241}

DOI: $10.26717 /$ BJSTR.2021.33.005400

Giorgio V. Biomed J Sci \& Tech Res

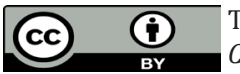

This work is licensed under Creative Commons Attribution 4.0 License

Submission Link: https://biomedres.us/submit-manuscript.php
4. Van Elburg RM, van den Berg A, Bunkers CM, van Lingen RA, Smink EW, et al. (2004) Minimal enteral feeding, fetal blood flow pulsatility, and postnatal intestinal permeability in preterm infants with intrauterine growth retardation. Arch Dis Child Fetal Neonatal Ed 89(4): F293-296.

5. Alessandri JM, Arfi TS, Thieulin C (1990) The mucosa of the small intestine: development of the cellular lipid composition during enterocyte differentiation and postnatal maturation. Reprod Nutr Dev 30(5): 551-576.

6. Giorgio V, Miele L, Principessa L, Ferretti F, Villa MP, et al. (2014) Intestinal permeability is increased in children with non-alcoholic fatty liver disease and correlates with liver disease severity. Dig Liver Dis 46(6): 556-560.

7. https://www.who.int/tools/child-growth-standards

8. Gervasoni J, Schiattarella A, Giorgio V, Primiano A, Russo C, et al. (2016) Validation of an LC-MS/MS Method for Urinary Lactulose and Mannitol Quantification: Results in Patients with Irritable Bowel Syndrome. Dis Markers 2016: 5340386.

9. Lostia AM, Lionetto L, Principessa L, Evangelisti M, Gamba A, et al. (2008) A liquid chromatography/mass spectrometry method for the evaluation of intestinal permeability. Clin Biochem 41(10-11): 887-892.

10. Hansen CF, Thymann T, Andersen AD, Holst JJ, Hartmann B, et al. (2016) Rapid gut growth but persistent delay in digestive function in the postnatal period of preterm pigs. Am J Physiol Gastrointest Liver Physiol 310(8): G550-560.

11. Kosek MN, Lee GO, Guerrant RL, Haque R, Kang G, et al. (2017) Age and Sex Normalization of Intestinal Permeability Measures for the Improved Assessment of Enteropathy in Infancy and Early Childhood: Results From the MAL-ED Study. J Pediatr Gastroenterol Nutr 65(1): 31-39.

12. Corpeleijn WE, van Elburg RM, Kema IP, van Goudoever JB (2011) Assessment of intestinal permeability in (premature) neonates by sugar absorption tests. Methods Mol Biol 763: 95-104. 